\title{
Measurement of Activity and Concentration of Paraoxonase 1 (PON-1) in Seminal Plasma and Identification of PON-2 in the Sperm of Boar Ejaculates
}

Isabel Barranco, Jordi Roca, Asta Tvarijonaviciute, Marie Rubér, Alejandro Vicente-Carrillo, Mohammad Atikuzzaman, Jose J. Ceron, Emilio A. Martinez and Heriberto RodriguezMartinez

\section{Linköping University Post Print}

\section{Tweet}

N.B.: When citing this work, cite the original article.

Original Publication:

Isabel Barranco, Jordi Roca, Asta Tvarijonaviciute, Marie Rubér, Alejandro Vicente-Carrillo, Mohammad Atikuzzaman, Jose J. Ceron, Emilio A. Martinez and Heriberto RodriguezMartinez, Measurement of Activity and Concentration of Paraoxonase 1 (PON-1) in Seminal Plasma and Identification of PON-2 in the Sperm of Boar Ejaculates, 2015, Molecular Reproduction and Development, (82), 1, 58-65.

http://dx.doi.org/10.1002/mrd.22444

Copyright: Wiley: 12 months

http://eu.wiley.com/WileyCDA/

Postprint available at: Linköping University Electronic Press

http://urn.kb.se/resolve?urn=urn:nbn:se:liu:diva-114595 


\section{RESEARCH ARTICLE}

Measurement of activity and concentration of paraoxonase (PON) 1 in seminal plasma and identification of PON-2 in sperm of boar ejaculates

ISABEL BARRANCO,${ }^{1}$ JORDI ROCA,${ }^{1 *}$ ASTA TVARIJONAVICIUTE, ${ }^{1}$ MARIE RUBÉR, ${ }^{2}$ ALEJANDRO VICENTE-CARRILLO ${ }^{2}$ MOHAMMAD ATIKUZZAMAN, ${ }^{2}$ JOSE J. CERON,${ }^{1}$ EMILIO A. MARTINEZ ${ }^{1}$ AND HERIBERTO RODRIGUEZMARTINEZ $^{2}$

${ }^{1}$ Department of Medicine and Animal Surgery, University of Murcia, Murcia, 30100, Spain

${ }^{2}$ Department of Clinical \& Experimental Medicine (IKE), University of Linköping, Linköping, SE-581 85, Sweden

*Corresponding author. Tel.: +34 868884735 .

E-mail address: roca@um.es (J. Roca).

Short title: Paraoxonase in boar semen

Grant sponsor: Ministry of Economy and Competitiveness of Spain and European Regional Development Fund, grant number: AGL2012-39903.

Grant sponsor: Swedish Research Council Formas, grant number: 2011-512.

Grant sponsor: Ministry of Education, Culture and Sport of Spain, grant number: FPU12/05008. 
Abbreviations: BTS, Beltsville thawing solution; HDL-C, high-density lipoprotein cholesterol; LDL-C, low-density lipoprotein cholesterol; LPO, peroxidation of membrane lipids; OS, oxidative stress; PBS, EDTA-free phosphate-buffered saline; PON, paraoxonase; ROS, reactive oxygen species; RT, room temperature; SP, seminal plasma. 


\section{ABSTRACT}

This study revealed and characterised the presence of the antioxidant enzymes paraoxonase (PON) type 1 (PON-1, extracellular) and type 2 (PON-2, intracellular) in boar semen. To evaluate PON-1, an entire ejaculate from each of ten boars was collected and the seminal plasma (SP) harvested after double centrifugation $(1,500 g ; 10 \mathrm{~min})$. SP was analysed for concentration as well as enzymatic activity of PON-1, and for total cholesterol levels. Intracellular PON-2 presence was determined via immunocytochemistry in spermatozoa derived from AI-doses. SP-PON-1 concentration ranged from 0.961 to $1.670 \mathrm{ng} / \mathrm{ml}$ while the enzymatic activity ranged from 0.056 to $0.400 \mathrm{IU} / \mathrm{ml}$, depicting individual variation. SPPON-1 concentration and enzymatic activity were negatively correlated $(r=-0.763 ; P<$ 0.01). Total SP cholesterol concentration was positively correlated with PON-1 activity ( $r=$ 0.773; $P<0.01)$ and negatively correlated with PON-1 concentration $(r=-0.709 ; P<0.05)$. Immunocytochemistry revealed that PON-2 localised to the post-acrosomal area of the sperm head and principal piece of the tail in membrane-intact spermatozoa. In sum, PON is present in boar semen, with PON-1 at low levels in SP and PON-2 within the spermatozoa. Further studies are needed to characterise the relationship between antioxidant PONs with sperm and other SP-parameters.

Keywords: Antioxidant; Boar; Enzyme; Semen.

\section{INTRODUCTION}


Boar spermatozoa produce a variety of reactive oxygen species (ROS) that play important physiological roles in the control of capacitation and concomitant tyrosine phosphorylation (Peña et al., 2004). However, if ROS exceed critical levels, the restricted antioxidant capacity of boar spermatozoa can be overwhelmed, resulting in oxidative stress (OS) (Awda et al., 2009), which in turn leads to peroxidation of membrane lipids (LPO) and sperm dysfunction (Guthrie and Welch, 2012). Boar spermatozoa have large quantities of polyunsaturated fatty acids in plasma membrane, low concentrations of intracytoplasmic ROS-scavenging enzymes, and often, high levels of ROS; therefore, they are particularly susceptible to OS (Cerolini et al., 2000; Radomil et al., 2011). Boar spermatozoa appear to require the antioxidant capabilities of the surrounding seminal plasma (SP) to supplement their limited intrinsic antioxidant defences (Bathgate, 2011).

Boar SP is composed of secretions produced in the rete testis, epididymis and male accessory sex glands, and it contains a wide of variety of factors acting as energy sources for the spermatozoa. SP also influences sperm functionality by protecting them from cold shock and improving their lifespan in the female genital tract (Rodriguez-Martinez et al., 2005; 2008). Components of porcine SP protect spermatozoa against OS by supplying antioxidants (Bathgate, 2011). These SP antioxidants include ROS scavengers such as the enzymatic antioxidants superoxide dismutase, catalase and the glutathione peroxidase/glutathione reductase system, and non-enzymatic antioxidants such as reduced glutathione, ascorbate, urate, pyruvate, taurine and vitamin E ( $\alpha$-tocopherol) (Saleh and Agarwal, 2002). These act to prevent genomic DNA fragmentation, block premature sperm maturation and control LPO of the sperm plasma membrane (Sanocka and Kurpisz, 2004).

Other cells types (e.g., macrophages) and fluids (e.g., blood plasma) contain putative potent antioxidants, among them the enzyme paraoxonase (PON). The PON enzyme family 
is functionally linked to cholesterol and is composed of three members: PON-1, PON-2 and PON-3 (Ng et al., 2006). The major function of PON is to prevent oxidation of Low-Density Lipoprotein Cholesterol (LDL-C) and subsequent endothelial OS (Ng et al., 2006; Marsillach et al., 2008; Camps et al., 2009). PON-1 and -3 are extracellular enzymes, present in blood plasma and bound to High-Density Lipoprotein Cholesterol (HDL-C) (Jaouad et al., 2006). Conversely, PON-2 is an intracellular enzyme not found in blood plasma ( $\mathrm{Ng}$ et al., 2001; Camps et al., 2009). PON enzymes have also been detected in a variety of tissues, including mouse testis, specifically in spermatogonia, spermatocytes and round and elongated spermatids (Marsillach et al., 2008). Additionally, PON-1 has been identified in human SP

(Verit et al., 2009; Marsillach et al., 2011), in bull ejaculate (Dedeoğlu et al., 2014) and in the SP of white leghorn layer breeders (Khan et al., 2012). In human SP, PON-1 levels are relatively low (Marsillach et al., 2011) but are related to OS in semen and infertility (Verit et al., 2009; Lazaros et al., 2011). Whether these innate enzymes with putative antioxidant properties are present in the SP (PON-1) or spermatozoa (PON-2) of other species remains to be explored. Therefore, this study aimed to characterise the presence of PON-1 and PON2 in boar semen.

\section{RESULTS}

Both SP-PON-1 concentration and enzymatic activity clearly differed among boars, ranging from 0.961 to $1.670 \mathrm{ng} / \mathrm{ml}$ and 0.056 to $0.400 \mathrm{IU} / \mathrm{ml}$, respectively, with a more obvious variation for enzymatic activity than for concentration (Fig. 1). A negative correlation $(P<0.01)$ was found between the concentration and enzymatic activity of SPPON-1 (Fig. 2). 
The ejaculate volume ranged from 92.5 to $349 \mathrm{ml}$ and sperm concentration between 220 and $378 \times 10^{6}$ sperm $/ \mathrm{ml}$. The activity of SP-PON-1 was negatively correlated with ejaculate volume $(r=-0.726, P<0.05)$ and positively correlated with sperm concentration $(r=0.654, P<0.05)$. Total cholesterol SP-concentration also varied among boars, ranging between 40 and $130 \mathrm{mg} / \mathrm{ml}$. Total amounts of SP-cholesterol were negatively correlated with SP-PON-1 concentration $(r=-0.709, P<0.05)$ but positively $(r=0.773, P<0.01)$ correlated with SP-PON-1 enzymatic activity.

PON-2 was identified in all examined sperm samples. Immunolabeling was specifically localised to the post-acrosomal region (Fig. 3c-d) independently of whether the plasma membrane was permeabilised or not.

\section{DISCUSSION}

This is the first study revealing the existence of PON in the semen of domestic boars. Specifically, we found PON-1 in the SP and PON-2 in the cytoplasm of spermatozoa. Furthermore, this study also revealed differences in SP-PON-1 concentration and enzymatic activity among boars, the latter of which showing the highest variation. SP-PON-1 enzyme concentration and enzymatic activity were negatively correlated. Moreover, while SP-PON1 concentration was negatively correlated with the amount of total cholesterol present in SP, the degree of SP-PON-1 enzymatic activity was positively correlated with total cholesterol levels.

Until the present study, where SP-PON-1 concentrations and activity were determined in boar semen, enzymatic activity had been determined in human (Verit et al., 2009; Marsillach et al., 2011) and in white leghorn layer breeders (Khan et al., 2012), with large variation among individuals and ejaculates within male. Such variation in measured 
enzymatic activity has been suggested as caused by presence of polymorphism in the coding and promoter regions of the PON-1 gene (Camps et al., 2009). Although variation was also registered in the present boar population, that of SP-PON-1 enzyme concentration varied less than that of measured enzyme activity, suggesting that other reasons than genetic polymorphism might be involved, including differences in substrate conversion. The concentrations of PON-1 were low, confirming previous studies (Verit et al., 2009; Marsillach et al., 2011). The SP of boar (and other mammals) is a complex mixture of secretions that originates from the testes, epididymis and the male accessory sexual glands, in which spermatozoa are suspended (Strzezek, 2002; Rodriguez-Martinez et al., 2005). The biochemical SP composition varies largely, both qualitatively and quantitatively, between breeds of boars as well as between boars of a same breed and even between ejaculates of the same boar (Strzezek et al., 2005). Specifically, differences in SP proteomics have been described (Rodriguez-Martinez et al., 2005; Saravia et al., 2009), and different SP protein profiles have been found between boars of different in vivo fertility (Flowers and Turner, 2001). Additional SP variation has been found in the ability of the semen sample to sustain cryopreservation (Roca et al., 2006). The differences that we have found between boars for PON-1 concentration and enzymatic activity follow similar patterns, although it is unclear whether the differences could have an impact on fertility or semen handling processes; hence, further studies are necessary to test this hypothesis. Similarly, further studies are also needed to elucidate the direct relationship between the SP-PON-1 enzyme activity and the sperm concentration, which could be mediated by the release of reactive oxygen species from sperm. In this regard, it is known that the presence of ROS in the medium (environment) is able to stimulate the activity of antioxidant enzymes. 
Our results showed that SP samples with lower PON-1 concentration had higher activity of this enzyme and vice versa. Similar divergences between PON-1 concentration and activity have been reported in human blood serum, of obese compared to non-obese children (Ferre et al., 2013). The enzyme PON-1 is an HDL-C-associated enzyme that protects LDL-C against oxidation, most likely by hydrolysing specific lipid peroxides, such as specific oxidised cholesteryl esters and phospholipids (Mackness et al., 1993; Aviram et al., 1999). The association of PON-1 with HDL-C is a prerequisite for maintaining normal activity of the enzyme, where HDL-C provides an amphipathic environment to shield the hydrophobic N-terminal region of the enzyme. Such an environment may also be necessary for normal interaction of PON-1 with its substrates. Moreover, PON-1 activity is highly dependent on the lipid and protein composition surrounding HDL-C particles (James and Deakin, 2004). These HDL-C particles may exert a more indirect influence on PON-1 function by sequestering oxidised lipids that could compromise enzyme activity (James and Deakin, 2010).

To confirm that such associations also occur in semen, we tried to determine HDL-C concentrations in boar SP-samples; however, the concentrations detected were lower than the limits of the detection assay. Similar results were obtained in men (Marsillach et al.; 2011) and bulls (Beer-Ljubić et al., 2009), suggesting that HDL-C in SP attains insignificant levels. Therefore, we measured total cholesterol levels, which include HDL-C, LDL-C and VLDLC (very low density lipoprotein cholesterol) (Birtcher and Ballantyne, 2004). The measurement of total cholesterol concentration could give us an approximation of the levels of HDL-C present in our samples. Cholesterol is a substantial component of sperm plasma membrane playing a key role in its permeability and fluidity. As presented, the SP-total cholesterol concentrations were positively and negatively correlated with PON-1 activity and 
concentration, respectively. Accordingly, it seems that PON-1 activity and concentration described two different events. Further studies could clarify their role and relationship with sperm quality. It would be interesting to measure the activity of the enzyme in relation to oxidation in SP because it was highly variable.

PON-2 was found in boar spermatozoa, specifically in the post-acrosomal region. Marsillach et al. (2008) revealed, through immunohistochemical analyses, the localisation of the PON proteins (including PON-1, 2 and 3) in mouse testis: in spermatogonia, spermatocytes and round and elongated spermatids. However, this is the first time that this enzyme has been identified in ejaculated spermatozoa. PON-2 has been identified in the cytoplasm of cells (Mackness et al., 1997; Shiner et al., 2007). The observed post-acrosomal and principal piece localisations are to be marked as cytoplasmic and would represent a relevant line of antioxidant defence against ROS overproduction. PON-2 antioxidant properties are similar to those of PON-1; lowering the intracellular OS, preventing LDL-C oxidation, reversing the oxidation of mildly oxidised LDL-C, inhibiting oxidised LDL-Cinduced chemotaxis and increasing cholesterol efflux (Ng et al., 2006). While serum PON-1 and PON-3 are inactivated during OS, PON-2 expression and activity are increased under OS, most likely as a compensatory mechanism (Aviram and Rosenblat, 2004). In addition, an overexpression of PON-2 reduces oxidative status and prevents apoptosis in vascular endothelial cells (Ng et al., 2001). It is well known that at low levels, ROS mediate normal sperm function such as capacitation, hyperactivation, acrosomal reaction and sperm-oocyte fusion, but at high levels, the increased production of ROS can cause OS and induce pathophysiological changes in the spermatozoa, causing peroxidative damage to the cell membrane and oxidative damage to mitochondrial DNA (Darmawan, 2007). PON-2 might 
not be enough to counteract exaggerated ROS levels per se, and thus the presence of PON-1 in the SP might play a major role.

In summary, we report the presence of paraoxonases in boar semen, PON-1 in SP and PON-2 in spermatozoa. We have also shown that SP-PON-1 enzymatic activity is positively correlated with total cholesterol levels. Hence, for the assessment of this enzyme, it would be more recommendable to quantify its enzymatic activity rather than its concentration. Further studies are required to investigate the role played by these respective enzymes as antioxidants and their relationship with sperm quality, functionality and fertility parameters.

\section{MATERIAL AND METHODS}

\section{Reagents and media}

All chemicals used in these experiments were of analytical grade. Unless stated otherwise, all media components were purchased from Sigma-Aldrich (St. Louis, MO, USA), and the media were prepared under sterile conditions in a laminar flow hood (MicroH;

Telstar, Terrasa, Spain). The basic medium used for sperm extension was Beltsville Thawing Solution (BTS: glucose 205 mM, $\mathrm{Na}_{3} \mathrm{C}_{6} \mathrm{H}_{5} \mathrm{O}_{7} 20.39 \mathrm{mM}, \mathrm{KCl} 10.0 \mathrm{mM}, \mathrm{NaHCO}_{3} 15.01 \mathrm{mM}$, EDTA $3.36 \mathrm{mM}$; pH 7.2 and 290-300 mOsmol/kg) supplemented with $50 \mu \mathrm{g} / \mathrm{ml}$ of kanamycin sulfate. EDTA-free phosphate-buffered saline (PBS: NaCl 139 mM, KCl 2.7 mM, $\mathrm{KH}_{2} \mathrm{PO}_{4} 1.5 \mathrm{mM}, \mathrm{Na}_{2} \mathrm{HPO}_{4} \cdot 7 \mathrm{H}_{2} \mathrm{O} 8.1 \mathrm{mM}$; with $0.058 \mathrm{~g} / \mathrm{L}$ penicillin $\mathrm{G}$ and $0.05 \mathrm{~g} / \mathrm{L}$ streptomycin sulphate; pH 6.8 and 280-300 mOsmol/kg) was used to dilute reagents.

\section{Animals and semen collection}


All procedures involving animals were performed according to international guidelines and were approved by the Bioethics Committee of Murcia University (research code: 639/2012).

Entire ejaculates were collected from mature and healthy boars of different breeds or crossbreeds housed at two commercial insemination centres in Spain (AIM Ibérica, Calasparra, Murcia) and Sweden (Quality Genetics, Hållsta). All boars were fertile and undergoing regular semen collection for the production of AI semen doses. All boars were subjected to the same housing conditions: individual pens in environmentally controlled (15$25^{\circ} \mathrm{C}$ ) buildings with windows allowing for exposure to natural daylight. Supplementary light was provided for a total of $16 \mathrm{~h}$ of light per day. The boars were provided ad libitum access to water and were fed commercial diets according to nutritional requirements for adult boars.

Ejaculates were collected using the gloved-hand method, extended (1:1, v:v) in BTS and evaluated for conventional semen characteristics. Volume was assessed using a graduated collection test tube. Sperm concentration was evaluated by hemocytometer after extending (1:10, v:v) an aliquot of semen with a $0.3 \%$ solution of formaldehyde in PBS. Proportions of motile spermatozoa in the BTS-extended semen samples (1:1, v:v) were subjectively evaluated by an experienced operator using light microscopy. Sperm morphology was assessed under a light microscope (Eclipse CI Series, Nikon Instruments Europe B.V., Amsterdam, Netherlands), and the proportions of sperm with normal morphology were determined by viewing wet mounts of extended semen fixed in a $0.3 \%$ solution of formaldehyde in PBS. All ejaculates contained more than $200 \times 10^{6} \mathrm{sperm} / \mathrm{ml}$, $70 \%$ motile spermatozoa and $75 \%$ of morphologically normal cells. 


\section{Seminal plasma processing and storage}

Ten millilitres of each ejaculate was transferred to $15 \mathrm{ml}$ tubes immediately following ejaculation to obtain the SP. The SP was harvested after double centrifugation at $1,500 \mathrm{~g}$ for 10 min (Rotofix 32A, Hettich Zentrifugen, United Kingdom). The second supernatant was always examined with light microscopy to ensure the absence of sperm before being sent in insulated containers $\left(15-17^{\circ} \mathrm{C}\right)$ to the Andrology Laboratory at the Veterinary Teaching Hospital of the University of Murcia. All SP-samples arrived within 2-4 h of ejaculate collection. At the laboratory, the SP-samples were frozen to $-80{ }^{\circ} \mathrm{C}$ (Ultra Low Freezer, Haier, Canada) and stored until thawed at room temperature (RT) for analysis.

\section{Measurement of PON-1 concentration in SP}

SP-PON-1 concentration was determined using a sandwich enzyme-linked immunosorbent assay following manufacturer's instructions (ELISA, Aviscera Bioscience Inc. Santa Clara, CA, USA). Briefly, a pre-coated microplate with monoclonal antibodies specific for PON-1 was used. Standards for the standard curve (ranging from 0.1-100 ng/ml, in 1:2 dilution) and SP-samples were added in duplicate to wells (100 $\mu 1)$ to bind PON-1 to the antibodies. In blank wells, dilution buffer was added. The plates were incubated for $2 \mathrm{~h}$ on an orbital shaker (Titramax 101, Heidolph Instruments GmbH \& Co., Schwabach, Germany) at $300 \mathrm{rpm}$, at RT. The contents of each well was aspirated and washed four times with $300 \mu \mathrm{l}$ wash buffer on an automated plate washer (Hydroflex, Tecan Austria GmbH, Grödig, Austria). The plate was blotted against clean paper towels to remove any remaining wash buffer, and detection antibody $(100 \mu \mathrm{l})$ was added and incubated for $2 \mathrm{~h}$, as described above. The plate was again washed prior to the addition of anti-Rabbit IgG-horseradish peroxidase conjugate $(100 \mu \mathrm{l})$ and incubation for $60 \mathrm{~min}$ in darkness. After another washing, 
Substrate Solution $(100 \mu 1)$ was added, and the plate was incubated for 2 min in darkness. Subsequently, $100 \mu 1$ of Stop Solution was added, and the optical density of the amount of substrate converted to product was detected at $450 \mathrm{~nm}$ using a micro-plate reader (Sunrise, Tecan Austria $\mathrm{GmbH}$ ), with a correction wavelength set at $540 \mathrm{~nm}$. For data acquisition and analysis, the software program Magellan v7.1 (Tecan Austria GmbH) and MyAssay.com (Five parametric logistic curves) were used. Values were expressed as ng/ml.

\section{Measurement of PON-1 activity in SP}

SP-PON-1 enzymatic activity was assessed in vitro, measuring the hydrolysis of pnitrophenyl acetate to p-nitrophenol in an automated analyser (AU 400, Olympus, Minneapolis, MN) adapting a previously described assay (Tvarijonaviciute et al., 2012) to SP. The p-nitrophenyl acetate is the recommended substrate for measuring PON-1 enzymatic activity in body fluids (Ceron et al., 2014). The SP samples were treated before analysis with acetazolamide $(0.5 \mathrm{mM})$ and diisopropyl fluorophosphate $(0.5 \mathrm{mM})$ to ensure that there were no contaminating enzymes other than PON-1 able to hydrolize p-nitrophenyl acetate. This assay revealed intra- and inter-assay coefficient variation lower than $10 \%$ and high linearity under serial dilutions and a limit of detection of $0.01 \mathrm{IU} / \mathrm{ml}$.

\section{Measurement of total cholesterol concentration in SP}

Total cholesterol presence in SP was quantified using an automated clinical chemistry analyser (Olympus AU2700, Olympus Diagnostica GmbH, Hamburg, Germany) following the manufacturer's instructions. In this procedure, cholesterol esters in a sample are hydrolysed by cholesterol esterase. The free cholesterol produced is oxidised by cholesterol oxidase to cholestene-3-one with the simultaneous production of hydrogen peroxide, which 
oxidatively couples with 4-aminoantipyrine and phenol in the presence of peroxidase to yield a chromophore. The red quinoneimine dye formed can be measured spectrophotometrically at 540/600 $\mathrm{nm}$ as an increase in absorbance.

\section{Immunocytochemical localisation of PON-2 in spermatozoa}

Sperm smears (three replicates) were prepared from commercial artificial insemination doses (enriched to $4.8 \times 10^{9}$ total spermatozoa) built up by the ejaculates from three boars (Hampshire breed) with good semen quality (see above). The smears were prepared 24 h post extension (Xcell, IMV, LÁigle France) on Poly-Lysine-coated glasses, fixed with $4 \%$ paraformaldehyde, washed three times with PBS and blocked with 5\% BSA in PBS for $2 \mathrm{~h}$. Thereafter, the samples were washed three times with PBS and incubated with the primary antibody (PON-2 Rabbit Polyclonal N-term antibody, Abgent, USA) diluted to $5 \mu \mathrm{g} / \mathrm{ml}$ in PBS with $1 \% \mathrm{BSA}$, in a wet chamber, at $4{ }^{\circ} \mathrm{C}$ overnight . Samples were then washed three times in PBS and incubated at RT in darkness with the secondary antibody (Polyclonal Goat anti-rabbit Alexa Fluor 568, Invitrogen, Molecular Probes Europe BV, Leiden, The Netherlands), diluted to $2 \mu \mathrm{g} / \mathrm{ml}$ in PBS containing $1 \%$ BSA, for $75 \mathrm{~min}$. Incubated samples were cover-slide mounted with antifade reagent Prolong Gold (Invitrogen) and visualised in a Zeiss Axioscop microscope (Zeiss, Germany) equipped with an epifluorescence module and a CCD Camera (Qimaging, Canada), accounting observation on 200 spermatozoa/slide. Permeabilisation was induced in complementary samples using Triton X-100 (0.5\% in PBS, pH 7.3) for 2-3 min at RT. In negative controls, the primary antibody was omitted, and in positive controls, incubated blood leukocytes were used.

\section{Experimental design}




\section{Experiment 1: Presence of PON-1 in boar SP}

PON-1 concentration and activity were measured in SP-samples from an entire ejaculate from each of ten boars. Additionally, total cholesterol concentration was also measured in the SP samples to assess its relationship with the activity and concentration of PON-1. Two separate measurements of each parameter were performed in each ejaculate.

\section{Experiment 2: Presence of PON-2 in boar spermatozoa}

PON-2 was determined in spermatozoa retrieved from commercial AI-doses prepared as pools of ejaculates (sperm-rich fraction) of three fertile, breeding boars. The AI-doses thus prepared contained $2.5 \times 10^{9}$ total spermatozoa extended with X-Cell (IMV) to an $80 \mathrm{ml}-$ volume. Each dose was shipped in an insulated container $\left(16-20^{\circ} \mathrm{C}\right)$ to Linköping University (Department of Clinical and Experimental Medicine, IKE). After arrival, aliquots of spermatozoa $\left(2 \times 10^{6} \mathrm{sperm} / \mathrm{ml}\right)$ were fixed in $4 \%$ paraformaldehyde in PBS, smeared onto Poly-lysine coated slides (ThermoFisher Scientific, Waltham, MA, USA) and dried overnight.

\section{Statistical analysis}

Statistical analyses were performed using IBM SPSS Statistics 19 (SPSS Inc.). The residual data for each variable were evaluated using the Kolmogorov-Smirnov test to check the assumption of normality. The relationships between concentration and activity of SPPON-1 and between both two and ejaculate parameters and total cholesterol SPconcentration were measured using the Pearson correlation test. Statistical significance was defined as $P<0.05$. 


\section{CONFLICT OF INTEREST STATEMENT}

None of the authors of this paper has a financial or personal relationship with other people or organizations that could inappropriately influence or bias the content of this paper.

\section{ACKNOWLEDGEMENTS}

The authors are grateful to AIM Iberica, Spain and Quality Genetics, Hllsta, Sweden for supplying boar semen samples. This work was supported by Ministry of Economy and Competitiveness of Spain and European Regional Development Fund (AGL2012-39903), Swedish Research Council Formas (2011-512) and Ministry of Education,Culture and Sport of Spain (FPU12/05008).

\section{REFERENCES}

Aviram M, Rosenblat M. 2004. Paraoxonases 1, 2, and 3, oxidative stress, and macrophage foam cell formation during atherosclerosis development. Free Radic Biol Med $37: 1304-1316$.

Aviram M, Rosenblat M, Billecke S, Erogul J, Sorenson R, Bisgaier CL, Newton RS, La Du B. 1999. Human serum paraoxonase (PON 1) is inactivated by oxidized low density lipoprotein and preserved by antioxidants. Free Radic Biol Med 26:892-904.

Awda BJ, Mackenzie-Bell M, Buhr MM. 2009. Reactive oxygen species and boar sperm function. Biol Reprod 81:553-561. 
Bathgate R. 2011. Antioxidant mechanisms and their benefit on post-thaw boar sperm quality. Reprod Domest Anim 46(Suppl. 2):23-25.

Beer-Ljubić B, Aladrović J, Marenjak TS, Laskaj R, Majić-Balić I, Milinković-Tur S. 2009. Cholesterol concentration in seminal plasma as a predictive tool for quality semen evaluation. Theriogenology 72:1132-1140.

Birtcher KK, Ballantyne CM. 2004. Measurement of cholesterol: a patient perspective. Circulation 110:296-297.

Camps J, Marsillach J, Joven J. 2009. The paraoxonases: role in human diseases and methodological difficulties in measurement. Crit Rev Clin Lab Sci 46:83-106.

Cerolini S, Maldjian A, Surai P, Noble R. 2000. Viability, susceptibility to peroxidation and fatty acid composition of boar semen during liquid storage. Anim Reprod Sci 58:99_ 111.

Ceron JJ, Tecles F, Tvarijonaviciute. 2014. Serum paraoxonase 1 (PON1) measurement: an update. BMC Vet Res 10:74.

Darmawan H. 2007. Production of ROS and its effects on mitochondrial and nuclear DNA, human spermatozoa, and sperm function. Med J Indones 16:127-133. 
Dedeoğlu N, Arslan M, Erzengin M. 2014. Purification of Holstein Bull Semen Paraoxonase 1 (PON1) by Hydrophobic Interaction Chromatography and Investigation of Its Inhibition Kinetics by Heavy Metals. Biol Trace Elem Res 158:29-35.

Ferre N, Feliu A, Garcia-Heredia A, Marsillach J, Paris N, Zaragoza-Jordana M, Mackness B, Mackness M, Escribano J, Closa-Monasterolo R, Joven J, Camps J. 2013. Impaired paraoxonase-1 status in obese children. Relationships with insulin resistance and metabolic syndrome. Clin Biochem 46:1830-1836.

Flowers WL, Turner ZA. 2001. Relationships between seminal plasma protein profiles and estimates of fertility for boars. In: VIth International Conference on Pig Reproduction, Greenville, Missouri, USA, pp. 65.

Guthrie HD, Welch GR. 2012. Effects of reactive oxygen species on sperm function. Theriogenology 78:1700-1708.

James RW, Deakin SP. 2010. The contribution of high density lipoprotein apolipoproteins and derivatives to serum paraoxonase- 1 activity and function. Adv Exp Med Biol 660:173-181.

James RW, Deakin SP. 2004. The importance of high-density lipoproteins for paraoxonase1 secretion, stability, and activity. Free Radic Biol Med 37:1986-1994. 
Jaouad L, de Guise C, Berrougui H, Cloutier M, Isabelle M, Fulop T, Payette H, Khalil A. 2006. Age-related decreased in high-density lipoproteins antioxidant activity is due to an alteration in the PON1's free sulfhydryl groups. Atherosclerosis 185:191-200.

Khan RU, Laudadio V, Tufarelli V. 2012. Semen traits and seminal plasma biochemical parameters in white leghorn layer breeders. Reprod Domest Anim 47:190-195.

Lazaros LA, Xita NV, Hatzi EG, Kaponis AI, Stefos TJ, Plachouras NI, Makrydimas GV, Sofitikis NV, Zikopoulus KA, Georgiou IA. 2011. Association of paraoxonase gene polymorphisms with sperm parameters. J Androl 32:394-401.

Mackness B, Hunt R, Durrington PN, Mackness MI. 1997. Increased immunolocalization of paraoxonase, clusterin, and apolipoprotein AI in the human artery wall with the progression of atherosclerosis. Arterioscler Thromb Vasc Biol 17:1233-1238.

Mackness MI, Arrol S, Abbott C, Durrington PN. 1993. Protection of low density lipoprotein against oxidative modification by high-density lipoprotein associated paraoxonase. . Atherosclerosis 104:129-135.

Marsillach J, Lafuente R, Checa MA, Maestre-Martinez C, Fabian E, Brassesco M, BeltranDebon R, Aragones G, Carreras R, Pedro-Botet J, Joven J, Camps J. 2011. Paraoxonase-1 is only present in traceable amounts in seminal fluid and does not show any relationship with male subfertility. BJU Int 108:566-570. 
Marsillach J, Mackness B, Mackness M, Riu F, Beltran R, Joven J, Camps J. 2008. Immunohistochemical analysis of paraoxonases-1, 2, and 3 expression in normal mouse tissues. Free Radic Biol Med 45:146-157.

Ng CJ, Hama SY, Bourquard N, Navab M, Reddy ST. 2006. Adenovirus mediated expression of human paraoxonase 2 protects against the development of atherosclerosis in apolipoprotein E-deficient mice. Mol Genet Metab 89:368-373.

Ng CJ, Wadleigh DJ, Gangopadhyay A, Hama S, Grijalva VR, Navab M, Fogelman AM, Reddy ST. 2001. Paraoxonase-2 is a ubiquitously expressed protein with antioxidant properties and is capable of preventing cell-mediated oxidative modification of low density lipoprotein. J Biol Chem 276:44444-44449.

Peña FJ, Johannisson A, Wallgren M, Rodriguez-Martinez H. 2004. Antioxidant supplementation of boar spermatozoa from different fractions of the ejaculate improves cryopreservation: changes in sperm membrane lipid architecture. Zygote $12: 117-124$.

Radomil L, Pettitt MJ, Merkies KM, Hickey KD, Buhr MM. 2011. Stress and dietary factors modify boar sperm for processing. Reprod. Domest. Anim. 46(Suppl. 2):39-44.

Roca J, Hernandez M, Carvajal G, Vazquez JM, Martinez EA. 2006. Factors influencing boar sperm cryosurvival. J Anim Sci 84:2692-2699. 
Rodriguez-Martinez H, Saravia F, Wallgren M, Roca J, Peña FJ. 2008. Influence of seminal plasma on the kinematics of boar spermatozoa during freezing. Theriogenology 70:1242-1250.

Rodriguez-Martinez H, Saravia F, Wallgren M, Tienthai P, Johannisson A, Vazquez JM, Martinez E, Roca J, Sanz L, Calvete JJ. 2005. Boar spermatozoa in the oviduct. Theriogenology 63:514-535.

Saleh RA, Agarwal A. 2002. Oxidative stress and male infertility: from research bench to clinical practice. J Androl 23:737-752.

Sanocka D, Kurpisz M. 2004. Reactive oxygen species and sperm cells. Reprod Biol Endocrinol 2:12.

Saravia F, Wallgren M, Johannisson A, Calvete JJ, Sanz L, Peña FJ, Roca J, RodriguezMartinez H. 2009. Exposure to the seminal plasma of different portions of the boar ejaculate modulates the survival of spermatozoa cryopreserved in MiniFlatPacks. Theriogenology 71:662-675.

Shiner M, Fuhrman B, Aviram M. 2007. Macrophage paraoxonase 2 (PON2) expression is up-regulated by pomegranate juice phenolic anti-oxidants via PPAR gamma and AP1 pathway activation. Atherosclerosis 195:313-321.

Strzezek J. 2002. Secretory activity of boar seminal vesicle glands. Reprod Biol 2:243-266. 
Strzezek J, Wysocki P, Kordan W, Kuklinska M, Mogielnicka M, Soliwoda D, Fraser L. 2005. Proteomics of boar seminal plasma-current studies and possibility of their application in biotechnology of animal reproduction. Reprod Biol 5:279-290.

Tvarijonaviciute A, Tecles F, Caldin M, Tasca S, Ceron J. 2012. Validation of spectrophotometric assays for serum paraoxonase type-1 measurement in dogs. Am J Vet Res 73:34-41.

Verit FF, Verit A, Ciftci H, Erel O, Celik H. 2009. Paraoxonase-1 activity in subfertile men and relationship to sperm parameters. J Androl 30:183-189. 


\section{Figures}

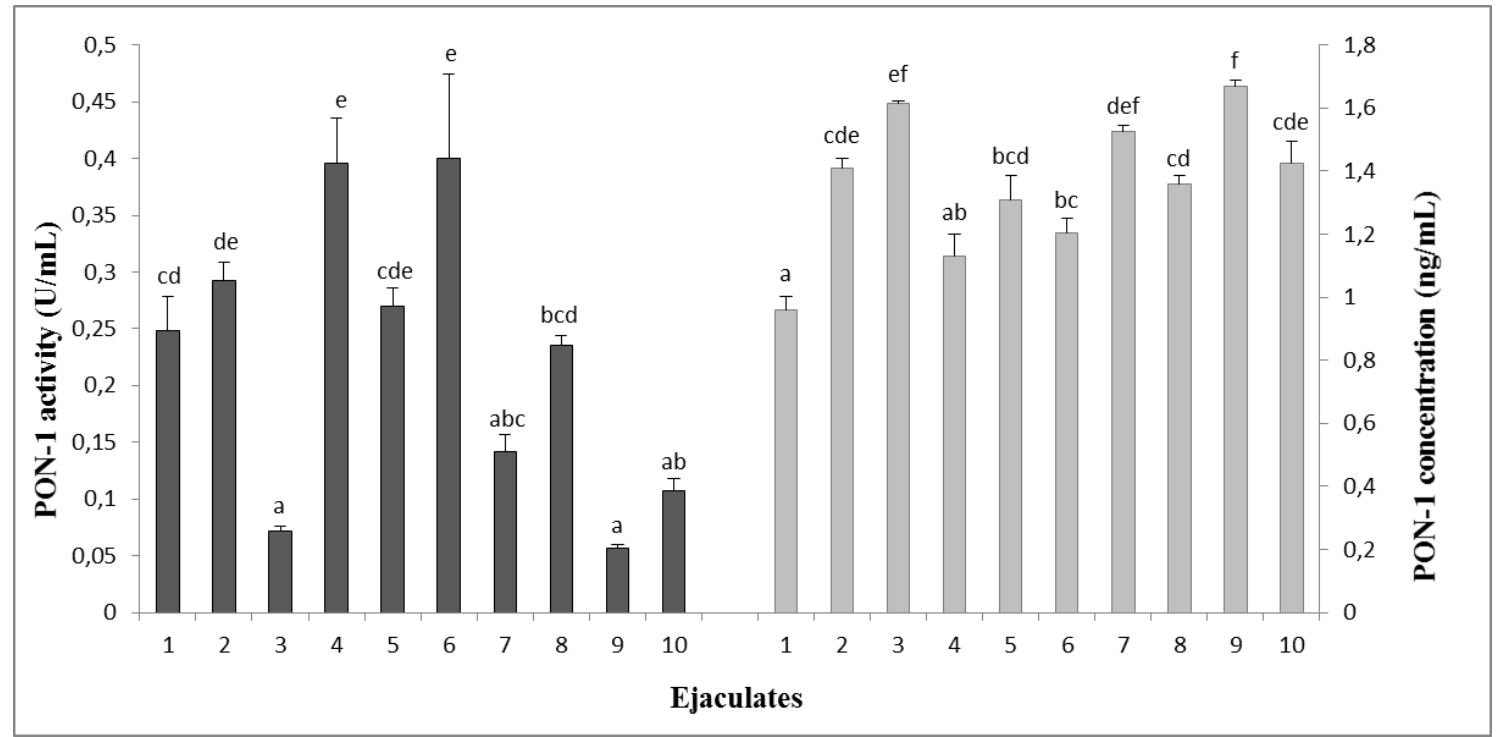

Figure 1. Paraoxonase type $1(\mathrm{PON}-1)$ enzymatic activity and enzyme concentration in boar seminal plasma samples from ten boars (one ejaculate per boar).

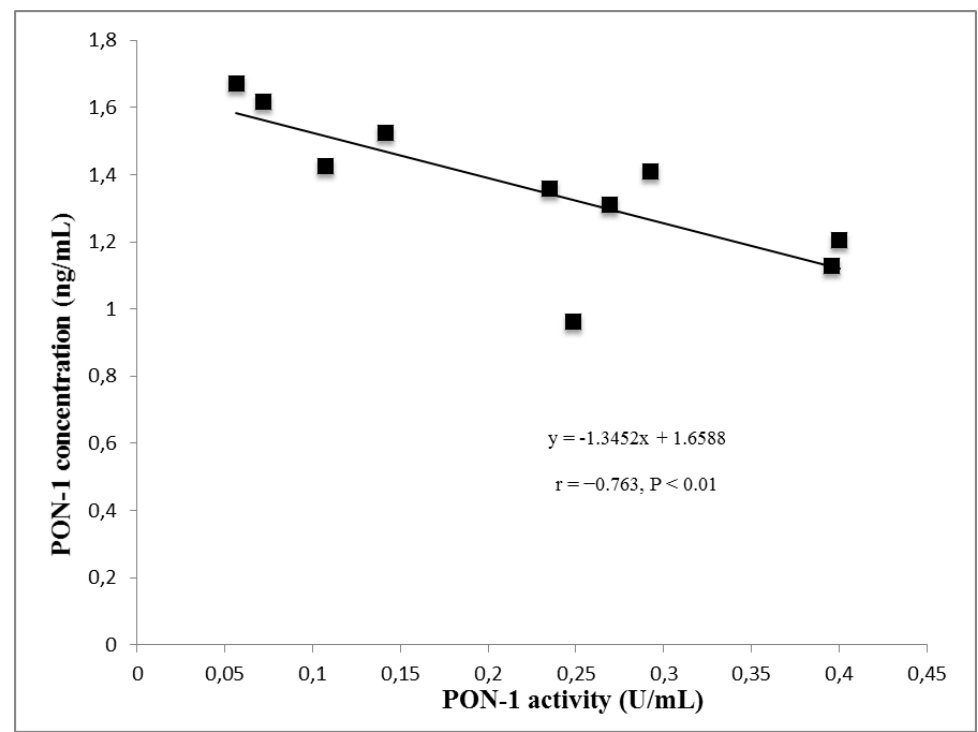

Figure 2. Correlation between Paraoxonase type 1 (PON-1) activity and concentration measured in boar seminal plasma samples from ten boars (one ejaculate per boar). 

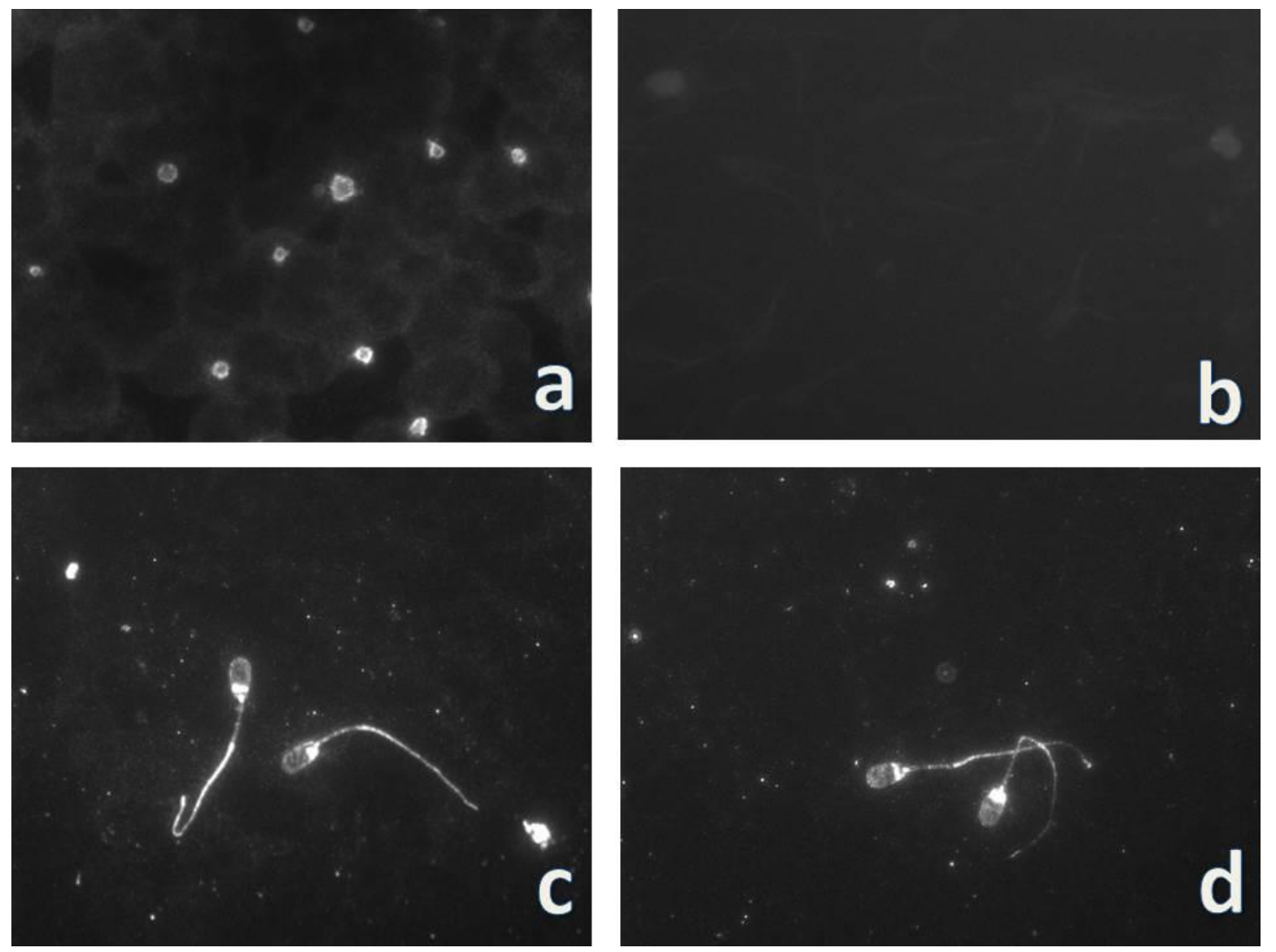

Figure 3. Immunocytochemisty of PON-2 in ejaculated boar spermatozoa. (a) Positive control, human blood leukocytes; (b) negative control, primary ab omitted; (c, d) postacrosomal localisation in non-permeabilised (c) or permeabilised (d) cells. Scale bars, $20 \mu \mathrm{m}$. 